\title{
HIV e Gestação: Estudo da Prevalência e Aspectos Epidemiológicos entre 436 Gestantes Atendidas no Pré-Natal do Hospital de Clinicas da Universidade Federal do Paraná no Periodo de junho de 1997 à março de 1998
}

Autor: Renato Luiz Sbalqueiro

Orientador : Prof. Dr. Newton Sergio de Carvalho

Dissertação apresentada para obtenção do título de Mestre em Tocoginecologia; Setor de Ciências da Saúde da Universidade Federal do Paraná em 8 de abril de 2000.

A infecção pelo Vírus da Imunodeficiência Humana (HIV) é uma preocupação mundial nos dias atuais, atingindo as mulheres principalmente em idade reprodutiva e tendo como uma de suas conseqüências a transmissão vertical. O objetivo do presente trabalho foi avaliar a prevalência da infecção pelo HIV entre as gestantes atendidas no Pré-Natal da Maternidade do Hospital de Clínicas da Universidade Federal do Paraná no período de junho de 1997 a março de 1998. Participaram deste estudo 436 gestantes que foram submetidas aos testes anti-HIV. Foram encontradas 9 pacientes com o teste positivo para o HIV, correspondendo a $2 \%$ do total. Destas, 7 gestantes tinham sido encaminhadas ao Pré-Natal por terem seu estado sorológico conhecido previamente. Quando excluímos estes encaminhamentos, obtivemos um percentual de $0,4 \%$. Todas as gestantes foram submetidas a um questionário padrão, no qual se procurou observar o seu perfil epidemiológico e de seus companheiros, que pudessem estar relacionados com a positividade para o HIV. As variáveis estudadas incluíam a idade da gestante, o número de gestações, a paridade, sua ocupação, local de procedência, e o número de parceiros sexuais. Também foi argüido sobre antecedentes de DST, transfusão sangüínea ou o uso de drogas injetáveis por elas ou por seus parceiros sexuais. Com referência a estes, ainda questionou-se a possibilidade deles terem tido relações homossexuais ou que fossem positivos para o HIV. Para análise estatística, os dados foram alocados em tabelas de duas entradas: uma relativa ao estado sorológico e outra, às variáveis sócio-demográficas acima descritas. A análise destas possiveis dependências foram testadas através do teste de Qui-quadrado, tendo como nivel de significância um $\mathrm{p}<\mathrm{ou}=\mathrm{a} 0,05$. Os resultados foram significativos, quando associamos a soropositividade para o HIV nestas gestantes e os antecedentes de DST e drogadição nelas e em seus companheiros e também uma positividade relacionada a homossexualismo em seus companheiros e naqueles HIV positivos.

Palavras-chave: AIDS. HPV. Drogadição.

\section{Estudo Comparativo do Perfil Biofisico Fetal antes e após o Tratamento da Crise Hipertensiva com a Nifedipina em Gestantes Hipertensas Crônicas e Avaliação dos Resultados Perinatais}

Autora: Maria Júlia Vieira de Oliveira

Orientador: Prof. Dr. Cézar Alencar de Lima Rezende

Tese de Mestrado apresentada ao Curso de Pós-Graduação em Medicina; Área de concentração: Ginecologia e Obstetrícia, da Faculdade de Medicina da Universidade Federal de Minas Gerais em 12 de novembro de 1999.

Com o objetivo de avaliar a vitalidade fetal antes e após o tratamento da crise hipertensiva com o uso da nifedipina, foram acompanhadas 32 pacientes que apresentaram crise hipertensiva nessa gestação, e um total de 566 com hipertensão arterial crônica, em um estudo do tipo coorte, no período de janeiro de 1995 a dezembro de 1996, na Maternidade Escola Hilda Brandão. A crise hipertensiva foi caracterizada pelos niveis pressóricos iguais ou superiores a $170 / 110 \mathrm{mmHg}$. Essas pacientes foram submetidas à avaliação fetal através do perfil biofísico, tratadas com $5 \mathrm{mg}$ de nifedipina sublingual (três gotas) e submetidas a uma nova avaliação desse perfil, aproximadamente 30 minutos após o controle da crise. Observou-se que o padrão do perfil permaneceu o mesmo antes e depois do tratamento $(\mathrm{p}>$ $0,05)$. As principais características do grupo de pacien- tes que desenvolveram crise hipertensiva foram: idade média 33,2 anos (mediana 34 anos), cor "não-branca" (87\%), multiparidade (média de 4,3 gestações), número insuficiente de consultas pré-natais (média 5,8 consultas) e tempo de diagnóstico da doença igual ou maior que quatro anos. Verificou-se que o tratamento da crise hipertensiva não alterou a vitalidade fetal, que a nifedipina foi uma droga eficaz no controle da crise hipertensiva e que a prematuridade e o baixo peso ao nascer foram as principais complicações do grupo de hipertensas com crise $(\mathrm{p}<0,05)$.

Palavras-chave: Complicações da gravidez. Hipertensão. Desenvolvimento fetal. Vitalidade fetal. Perfil biofísico fetal. 


\section{Estudo Anátomo Clínico do Carcinoma de Paget da Mama}

Autor: José Costa Andrade

Orientador: Prof. Dr. Laurival A. De Luca

Dissertação apresentada à Faculdade de Medicina de Botucatu - Unesp, em 3 de dezembro de 1999.

O objetivo deste trabalho foi estudar os múltiplos aspectos do Carcinoma de Paget da mama. Patologia especial e rara foi abordada, do ponto de vista clínico, anátomo patológico e terapêutico, chamando a atenção dos oncologistas para esta importante doença. Foram estudados retrospectivamente 98 pacientes, tratados no Instituto de Controle do Câncer - IBCC, no período entre janeiro de 1980 a dezembro de 1998. Avaliamos a incidência, idade, estadiamento clínico, diagnóstico, anatomia patológica e tratamento. Dos 6.303 casos de câncer de mama tratados, a incidência do Carcinoma de Paget foi de 1,55\%, sendo 97 do sexo feminino e um do sexo masculino. A idade variou entre 20 e 90 anos, com média de 56,9 anos, o pico mais alto de freqüência foi observado na faixa etária de 50 a 60 (32,6\%). Dos 98 casos estudados, 77 (78,57\%) evidenciaram a doença e 21 pacientes $(21,42 \%)$ eram portadoras de Carcinoma de Paget subclinico. Apresentavam somente lesão cutânea no complexo aréolo mamilar 31 casos $(31,63 \%)$ e 67 (68,37\%) apresentavam tumor palpável. A metástase axilar foi observada em dois casos $(2,04 \%)$ no grupo que apresentava só lesão cutânea. No grupo com tumor palpável foi de $53,73 \%$. Quanto ao tratamento, a cirurgia é a melhor opção terapêutica, sendo a mastectomia tipo PateyMerola a preferida pela maioria dos autores. A radioterapia, a quimioterapia e hormonioterapia são utilizadas como tratamento complementar, quando a opção é a cirurgia conservadora e nos casos avançados. O Carcinoma de Paget da mama, embora de baixa incidência, possui grande importância na oncologia mamária. Apesar da exuberância dos sinais clínicos, há inaceitável retardamento no diagnóstico. A maioria das lesões está sempre associada ao carcinoma ductal infiltrativo.

Palavras-chave: Doença de Paget da mama. Câncer da mama: diagnóstico. Câncer da mama: tratamento.

\section{Aspectos Citopatológicos de Fluido Peritoneal na Endometriose Pélvica e suas Relações Endoscópicas, Histopatológicas e Imunocitoquímicas.}

Autor: José Eleutério Junior

Orientador: Prof. Dr. Francisco Valdeci de Almeida Ferreira

Dissertação apresentada ao Curso de Pós-Graduação em Patologia do Departamento de Patologia e Medicina Legal da Faculdade de Medicina da Universidade Federal do Ceará, para obtenção do Título de Mestre, em 18 de agosto de 2000.

Com a finalidade de avaliar parâmetros citopatológicos e imunocitoquímicos da endometriose pélvica, foram estudados esfregaços de sedimento de fluido peritoneal, corados por métodos de Papanicolaou e MayGrüwald-Giemsa, de 80 pacientes submetidas a laparoscopia diagnóstica em um período de três anos $(57$ com endometriose e 23 com outros diagnósticos que não o de endometriose). À partir de esfregaços de arquivo foi feito imunocitoquímica para receptores de estrógeno e progesterona, e de MIB-1. Na análise citológica observou-se que os achados de células tipo endometrial, hemossiderófagos e ambos elementos mostraram sensibilidade de 19,3\%, 64,9\% e 15,7\%, e especificidade de $86,9 \%, 86,9 \%$ e $95,6 \%$, respectivamente. Os valores preditivos positivo e negativo foram, para células tipo endometrial, $78,5 \%$ e $30,3 \%$, para hemossiderófagos, $92,5 \%$ e $50 \%$ e para ambos de $90 \%$ e $31,4 \%$, respectivamente. A taxa de probabilidade po- sitiva para hemossiderófagos foi a melhor $(12,3)$. Em 26 casos foi feito imunocitoquímica para receptor de estrógeno (RE), receptor de progesterona (RP) e MIB1. Observou-se expressão média semelhante para $\mathrm{RE}$ (4,3\% entre as endometrióticas e $5 \%$ no grupo controle). Apenas um caso no grupo de endometriose foi positivo para RP. MIB-1 em células tipo endometrial também teve expressão semelhante entre os grupos. Nos macrófagos, MIB-1 teve expressão média no grupo com endometriose igual a $9,3 \%$ e no grupo controle a expressão média foi $4,4 \%(\mathrm{p}<0,0001)$. Assim, é sugerido que hemossiderófagos e atividade proliferativa macrofágica, identificada por MIB-1, estão relacionados ao diagnóstico da endometriose pélvica.

Palavras-chave: Fluido peritoneal. Endometriose. Imunocitoquímica. 


\section{Perfil Clínico - Epidemiológico da Gravidez em Mulheres de 40 Anos ou mais.}

Autor: Ivo Silva Lima

Orientador: Profa. Dra. Olivia Lúcia Nunes Costa

Dissertação apresentada ao Colegiado do Mestrado em Assistência Materno - Infantil, da Faculdade de Medicina da Universidade Federal da Bahia, como pré-requisito obrigatório para obtenção do grau de Mestre em Assistência Materno-Infantil em 27 de outubro de 1999.

Este trabalho atualiza e descreve a idade da mulher como fator de risco na gravidez e para o recém-nascido. Realizou-se um estudo descritivo clínicoepidemiológico de 827 prontuários de parturientes de 40 ou mais anos e como grupo controle 4.947 prontuários de gestantes com a idade entre 25 a 30 anos, atendidas entre janeiro de 1990 e janeiro de 1995 na Maternidade Tsylla Balbino (MTB), Salvador, Bahia. Evidenciou-se neste trabalho que $89,7 \%$ das mulheres de 40 ou mais anos (grupo de estudo) que procuraram a maternidade para atendimento ao parto ou ao abortamento estavam na faixa entre 40 e 45 anos. A maioria das parturientes, seja no grupo de 40 ou mais anos $(97,6 \%)$ como no grupo de 25 a 30 anos $(99,3 \%)$ não apresentaram quaisquer intercorrências clínicoobstétricas durante o parto. As mulheres acima de 40 anos que não apresentaram intercorrências clínico- obstétricas durante a gravidez e parturição deram à luz a recém-nascidos em boas condições clínicas e com pesos equivalentes aos do grupo controle. A prevalência de abortamentos à época do atendimento obstétrico foi de $27,0 \%$ nas pacientes do grupo de estudo, superior aos $22,6 \%$ do grupo controle. Dentre as complicações apresentadas pelas mulheres do grupo de estudo, as mais freqüentes foram: hipertensão arterial crônica e doença hipertensiva especifica da gravidez. Como conseqüência desses estados patológicos, essas mulheres tiveram maior índice de recém-nascidos prematuros $(6,4 \%)$ em comparação com $2,7 \%$ nas mulheres jovens.

Palavras Chaves: Gravidez normal. Hipertensão arterial.

\section{Infecção Cervical Causada por Chlamydia Trachomatisem Gestantes. Estudo de Prevalência e} Fatores de Risco.

Autor: Rita de Cássia da Silva Leite
Orientador: Prof. Dr. Marcos Mendonça

Dissertação apresentada à Faculdade de Medicina da Universidade Federal de Minas Gerais - Área de Concentração em Ginecologia e Obstetrícia em 17 de dezembro de 1999.

O objetivo deste estudo foi o de estabelecer a prevalência da infecção cervical causada por Chlamydia trachomatis em gestantes normais e identificar possíveis grupos de risco na população. Trata-se de estudo prospectivo no qual foram incluídas 217 gestantes atendidas no Pré-Natal do Ambulatório Affonso Silviano Brandão, da Faculdade de Ciências Médicas de Minas Gerais, no período de março a outubro de 1999. O diagnóstico da infecção baseou-se no exame de PCR (Reação em Cadeia da Polimerase). Os resultados foram analisados estatisticamente utilizando-se o teste $\mathrm{t}$ de
Student e o teste exato de Fisher ou teste do Quiquadrado. A prevalência de infecção por C. trachomatis foi de 10,2\%, ou seja, das 217 pacientes estudadas, 22 apresentaram PCR positivo e 194 PCR negativo (uma paciente foi excluída do estudo). O presente estudo não caracterizou, nessa população, grupos de risco para infecção por Chlamydia trachomatis.

Palavras-Chave: Infecção na gravidez. Chlamydia trachomatis. Cervicites. 